these bave not seldom been men who would never have been selected as representatives by any conceivable parliament of British gynæcologists.

I remember well the presentation of the invitation from Great Britain to the Congress at Geneva. The deputation consisted essentially of two official members of the British Gynæcological Society who were notoriously antagonistic to the Obstetrical Society. And it should be remembered that the invitation presented at Amsterdam was merely a renewal of that given at Geneva. Dr. MacNaughton Jones and his colleagues appear to think that they play a trump card when they call attention to the fact that the invitation was presented at Amsterdam by Dr. Robert Barnes. Still, men have an awkward way of looking at the true inwardness of things, and not at mere formuli; and the result of that honest examination of the situation was the remonstrances from America and by no means cryptic hints from many other quarters, as to the need for a working arrangement with the Obstetrical Society. These hints were ignored until it was discovered that arrangements which could be made apparently to succeed at meetings in foreign capitals would not suit a congress held in London. Hence, obviously, the too belated proposal of coöperation made to the Obstetrical Society. In some journals which have been sent to me I regret to read injurious references to the action of the lecturers and teachers of obstetrics and gynæcology of the London medical schools. Epithets are not arguments which tend to conciliation. The unanimity of these teachers and their dignified expression of refusal to take part in a congress for which important arrangements had been already completed is an impressive fact which should form food for reflection, not a subject for reviling and sarcastic levities.

The question still remains: Can anything yet be done to put British gynæcology in its proper place in the opinion of the specialists of Europe and America, and to bring about some tiue the holding of a creditably successfnl International Congress in England? As a provincial specialist knowing the opinions of many men similarly situated, who, like myself, are not conscious of envy or jealousy even towards London colleagues, I would submit that the time has long gone by when London societies conld justly arrogate to themselves the right to speak for British gynæcology. Any truly representative body must have a wider basis. To be practical I would suggest something like the following, if the game be generally thought worth the candle. Let the honorary secretaries of all the existing Societies of Obstetrics and Gynæcology in the United Kingdom of Great Britain and Ireland form a convening committee to start with. It should be the function of this committee to form a grand committee of the members of these societies. Each of the societies could send a sufficient number of delegates to a meeting in London or elsewhere, as might be agreed, to elect an executive committee, or themselves to form an executive committee, to deal with the question of an international congress and other matters. If from this movement a great comprehensive society, on the model of the German Gynæcological Society, were to take shape and development so much the better. It would be premature to suggest further details. If among the specialists in obstetrics and gynæcology of the United Kingdom there is sufficient goodwill the way will be found.

I am, Sirs, yours faithfully.

Manchester, June 30th, 1900. W. J. SINCLAIR.

\section{"THE RELATIONSHIP OF MALARIA AND THE MOSQUITO."}

\section{To the Editors of THE LANCET.}

SIRS,-The interesting letter by Dr. Dauber in THE LANCET of June 23rd (p. 1834) requires a rather full reply, as his opinions are certainly shared by a considerable number of medical men, both in this country and the tropics. I trust that you can allow me sufficient space to deal with his arguments in some detail.

While admitting that "mosquitoes may frequently act as alternative or intermediary [he means definitive] hosts with man of the malaria parasite," he demurs to the dogma that the bite of Anopleeles constitutes the only mode of infection. I should say at once that no one can as yet be absolutely certain that there is no other mode of infection. We differ only as to the degree of probability which attaches to the bypothesis that there is another mode of infection. Koch and the Italians think that there is very little probability at all in favour of this view. Manson and Laveran are more inclined towards it. Your correspondent, with many others, tends to the other extreme and still believes in the miasma plus the mosquito. Speaking for myself I must confess that I think it extremely unlikely that there is another route of infection besides the bite of the mosquito; I have met neither with facts nor with what appear to me to be sound arguments in favour of such a thing; while there are many extremely cogent arguments against it. At the same time I keep a perfectly open mind on the subject, and am quite willing to be converted by any good evidence which may be addaced in the future.

No one accustomed to sifting scientific evidence will, fancy, be quite prepared to accept Dr. Dauber's. In order definitely to prove that a given outbreak of fever is not due to Anopheles it must clearly be shown that 1 nopheles were not present when the original infections occurred. It must also be certain that the cases of fever under consideration were first infections and not relapses; and, of course, that the disease was really malarial fever is a point which must have been established by microscopical methods before the case can be admitted into court. But your correspondent gives no precise details of this nature. He talks about "fever" and "swarms of mosquitoes" without specifying what fever and what mosquitoes. His instances appear to be based on very indefinite information. Even if his facts be admitted they often point in just the opposite direction to what he supposes, while he himself seems to think that popular impressions carry the force of experimental evidence. I will take his instances in the order in which he gives them. He quotes in support of his opinions a medical work in which "a chill, a wetting, the turning over of virgin soil, exposure, and fatigue are credited with causing fever as well as direct infection from mosquitoes." I hope that this medical work did not intend to imply that a malarial infection, a parasitic. invasion, can be caused by a chill. One might as well say that round worms are produced by a chill. What I suppose the medical work really means is that a relapse may be precipitated by a chill, by fatigue, and so on - a thing with which we are familiar in many diseases and which bas nothing to do with the original entry of the infecting parasites. I will deal later with the case of the "virgin soil." Dr. Dauber then proceeds to quote a writer in the Times who talks about the insalubrity of Pretoria and thinks that "the miasmas at sunset, attended by a bone-piercing cold, are especially dangerous." This is no evidence. The writer in the Times, voicing the popular idea, may believe in miasmas if he likes; but this does not go far to prove that they exist. What investigations has the writer in the Times made on the subject? As a matter of fact he seems to think that the miasmas arise from the "filthy habits of the genuine Boer"-a novel source for malaria. The writer in the Times may be Brown, Jones, or Robinson-the question is whether he knows anything at all about the matter. Next, your correspondent discusses the immunity which is supposed to be enjoyed by those who sleep at some height above the ground. He refuses to accept the explanation given by the theory that the mosquito is "a low flyer," because his own experience is opposed to this theory. Here we have a simple clashing of observation. The Italian observers -as well as myself-who have all been making a special study of mosquitoes for years, are quite convinced that mosquitoes often do prefer ground-floors to upper storeys. Apart from this, the question whether such immunity really exists is open to discussion. I fear we can hardly accept the authority-which Dr. Dauber quotes-of Kingsley's novel of "Westward Ho." If, as your correspondent adds, landing-parties in the navy "are instructed to make elevated platforms with boughs on which to sleep, and are supplied with axes for the purpose," this proves nothing. I have never known Government medical regulations cited as being medical authority of any value. Personally I should prefer the authority of "Westward. Ho."

In British Guiana, Dr. Dauber says, "Young men freshly arrived from the temperate climates, although they would be bitten more voraciously than the older residents, yet were not very liable to malarial fever until they had resided about a year in the country." This is a most unfortunate argument, because, like the Irishman's pig, it goes in a precisely opposite direction to that which is intended. Obviously the longer a man has resided in a 
mosquito country the greater the number of mosquito bites from which he has suffered from the commencement of his stay there, and the greater therefore his chances of having been bitten by an infected mosquito. If only one mosquito in a thousand is infected (which is quite possible), a man may well reside a year in a place before meeting his fate. On the other hand, if the poison lies in the soil, why are not these young men all infected the moment they land? Dr. Dauber thinks that "fresh arrivals bitten from head to foot and living amongst men constantly down with fever" whould become infected at once; he again omits to note whether he refers to the bites of Culex or 1 nopheles.

A number of instances are given where malarial fever was supposed to be due to turning up "virgin soil." These are of the usual indefinite kind. Was the fever malarial fever (and not, for instance, ankylostomiasis-which is an earthborne disease, and is frequently mistaken for malaria)? Were the cases original infections and not relapses due to chill and fatigue caused by the labour? Were Anopheles certainly absent? These questions must be answered before the evidence is worth a straw. It is no use quoting Mark Twain and describing public impressions at the time. Dr. Dauber adds that while the troops engaged in excavations at Hong-Kong suffered greatly from malaria the "Argyll and Sutherland Highlanders also stationed there at the same time, who were not engaged in the excavation works, did not suffer similarly"; and he continues with the remark that "It is hard to believe that the mosquitoes could make a differential diagnosis between the Engineers and the Highlanders." Certainly this would be hard to believe if the Engineers and the Highlanders lived intermixed in the same barracks and slept in the same rooms. Are we to understand that this was the case? If not, where is the point of the remark? Everyone who knows anything of the matter is aware that there may be crowds of Anopiceles in one house or barrack and few in the next (as at the Wilberforce barracks in Sierra Leone), or none at all a few hundred yards away. Your correspondent seems to imagine that mosqaitoes are a uniformly diffused entity like a gas. It is quite possible that the Engineers lived in sheds or houses infested with Anophcles, while the Highlanders did not; at least this point must be settled before the instance is of any value at all as evidence. Dr. Dauber's reference to the general paucity of mosquitoes at Hong-Kong is rather unfortunate in view of the recent find of Anopheles there by Mr. Ladds. His attempt to dispose of their breeding pools by quoting the words of an Engineer officer who says that no pools remain after heavy rain, is also scarcely what we call scientific evidence nowadays, and is moreover summarily dis. credited by the work of Mr. Ladds-to which I refer your correspondent. Then he quotes an officer of the Ashanti expedition of 1873-74 to the effect that in those parts "there is any amount of malarial fever but practically no mosquitoes." Really, this is the old old story. It was like the story I was told - and by a medical man too-that there are no mosquitoes in Sierra Leone! During the last few months I have heard the same absurd statement about every town on the West Coast of Africa, the fact being, of course, that many people never observe anything at all, not even a mosquito bite. Your correspondent next relates the case of a hospital ship, the Simoon, on which after a time malarial fever became endemic, infecting, for instance, the wounded returning from the expedition just mentioned. The Simoon was conciemned and replaced by the Victor Emmanuel which remained healthy. "If mosquitoes were the means of conveying infection in the first vessel," exclaims Dr. Dauber, "why were they not also in the second?" Possibly for the simple reason that there were no mosquitoes, or at least no Anopheles, in the second vessel. It must surely be remembered that $A$ nopheles, Jike many other insects, have their seasons. Moreover, the same case would tell equally against the idea that the malaria lay in the air of the locality in which the two vessels were stationed.

Next we hear the case of H.M.S. Active, from which a punitive expedition was sent up the Niger in a steamer. The expedition remained quite well until it returned to the Active, which then put to sca. Within a week after she had put to sea "nearly all of those who had taken part in the expedition were down with fever of a severe type." What point is there in this story? Dr. Darber seems to forget that in malarial fever, as in other diseases, there is an incubation period-lasting up to three weeks. I suppose that the members of the expedition were infected before they returned to the -1ctive and that the disease appeared in them some time afterwards-that is all. The case appears simple enough. Unless, indeed, the members of the expedition brought some freshly turned virgin soil with them I do not see that it applies to the question at issue. How explain it better on the supposition that malaria exists in the ground, for instance?

The disappearance of malarial fever in England affords your correspondent another text-since mosquitoes, even Anopheles olaviger, remain in England (which is true) how is it that the fever has disappeared so entirely? Precisely, and the answer gives perhaps one of the most serious blows to the soil theory. It is very well to talk largely and vaguely of the effects of drainage of the soil in England, but let us inquire more particularly. Are we to suppose that every square yard of soil in England has been drained? I suppose that there are a few ill-drained fields and ditches still remaining even in England. If so, why have the parasites which by hypothesis live in such places gone so completely? Surely there must be a patch of soil here and there which still contains its hordes of malaria germs. Surely a chance labourer may now and then happen to dig in such spots of ground, and should therefore contract the disease. It will not do; if the germ ever lived in British soil it is most highly improbable that it could have vanished so rapidly and completely as it has vanished. On the other hand, the mosquito theory affords a simple explanation of the phenomenon. According to it both Anopheles and malaria cases must be in sufficient numbers for the former to have a reasonable chance of becoming infected from the latter. But what has happened? The fever cases have been consistently reduced with quinine, while simultaneously the Anopheles have been reduced by drainage. The chances are now thousands to one against an Anoplueles ever biting a person suffering from malarial fever in England-more probably millions to one. But I will not anticipate some important researches which I hope will shortly be pablished on the subject.

Your correspondent does not think that the mosquito theory sufficiently explains the connexion of malaria with rainy seasons or rank vegetation. That is a mere matter of opinion. He says that though mosquitoes teem up the river Parana in South Africa-mosquitoes probably of all kindsyet fever is little prevalent there. This is not definite enough: we must know for certain that Anopheles do not exist at the exact spot where malaria prevails before the evidence has any validity. He avers that an offshore wind can induce an outbreak of malarial fever in vessels lying 50 miles from land. The records of such cases would be interesting ones, and I hope that your correspondent will find the time to publish them. Until then we must be excused if we scarcely admit with Dr. Dauber that such instances "prove conclusively that the atmosphere has some intimate connexion with the disease." He adds that he find it difficult to explain on the mosquito theory how "it is only the land breeze which does the mischief." Admitting the statement (which may, however, be doubted) I suppose it may be explained on the ground that the land breeze is more likely to carry the mosquitoes from the land to the ship than is a wind in the opposite direction. Lastly, he says that the paludal, miasmatic, and telluric conditions are still believed in in the British navy. I do not doubt it; they will doubtless be believed in by the British navy for the next hundred years.

I have now examined, I think, all of Dr. Dauber's instances and arguments and have done so at such length chiefly because similar views are continually being expressed by medical men in spite of all refutations. Such views appear to me to have a certain old-world flavour about them-smacking of the pleasant days when direct observation and experiment were not zet necessary in medical science, when we based our conclusions on obsolete text-books, hearsay evidence, and travellers' tales, and when a medical man could gain a reputation in tropical medicine on the strength of possessing a stuffed crocodile in his consulting-room. 1 do not mean to say that all such views are wrong, but certainly all of them are not right, and what I wish to impress is that they have little value as scientific evidence in the sense in which we now understand it. If the malarial miasma really exists its existence must be demonstrated not by citations of popular beliefs but by exact scientific work. Meantime our position is quite clear. Dr. Dauber blames us for inculcating the destruction of mosquitoes and so on without reference to precautions against the miasma. But this is quite logical. We are sure that 1 nopheles communicate the 
disease and we therefore devise measures against them. We know nothing for certain about other modes of infection and we therefore refuse to advise precautions against them. We cannot accept popular beliefs as being in any way equivalent to scientific demonstrations.

As a matter of fact, your correspondent has quite overlooked (although he nearly touches it once) the train of argument which is most fatal to the miasma hypothesis-I mean the arguments based on comparative parasitology. We are now familiar with a very large number of animal parasites and we recognise that their development and life-history proceed in accordance with certain general laws. Those whicb, like the parasites of malaria, pass between alternate hosts, possess a complicated development which enables them to do so. But there their development ceases. They do not also possess properties or organs which enable them to live in half-a-dozen other media as well. The life-cycle of the parasite of malaria is already complete according to these biological laws, and we have no justification for supposing that it possesses other life-cycles fitting it to live in the soil, or in the marsh, or in the air. We may as well suppose the same thing of tapeworms or trichinæ. The idea that any parasitic organism breeds indefinitely, say in the soil of an uninhabited locality, ready to pounce out upon the first man who happens to dig there, is a zoological absurdity. Moreever, the method of inoculation which nature has discovered for the malaria parasite is so simple and yet efficacious that those who have studied the wonderful arrangements by which it is brought about are not disposed to look with much favour on the clumsy ideas of the miasma and the telluric emanation.

Liverpool, July 1st, 1900. I am, Sirs, yours faithfully, where mosquitoes " teem in their millions and billions" and yet malaria is so uncommon, seems more unfortunate than I suspected at first. I wrote on the subject to Mr. F. V. Theobald, of the British Museum, who is collecting the known information about mosquitoes, and have just received the reply which he was kind enough to send me. After mention. ing the species of Anopheles found in that region, he adds: "This is all I can recall. It wonld thus seem that 1 nopheles are not common in those parts of South America-very different to what we find in the Malay Peninsula, West Coast of Africa, India, \&c."

\section{"THE NATIONALISATION OF TRINITY COLLEGE, DUBLIN."}

To the Editors of THE LANCET.

Sirs,-In The Lancet of June 30th a correspondent over the signature "A.M., M.D., Dub. University" writes : "Although I am unable to discern that the columns of a medical journal are the proper arena for the discussion of the Irish Catholic University question I feel bound to contest your conclusion as set forth in an annotation in THE LANCET of June 23rd, p. 1815, that the proposal to nationalise Trinity College is 'as useless as it is impracticable." "Now if your correspondent will look again at the annotation he refers to be will see it is entitled "Irish University Education"; that is, the paragraph deals with the question of Irish University education as a whole and not merely with that portion in which Roman Catholics are specially interested. Further, in the discussion of university questions whether they affect the whole or only a portion of the inhabitants of a country, your readers must admit that the interests of the medical faculties, which now constitute such large and important departments of all universities, demand most careful consideration; and where can questions affecting these medical departments be moro appropriately discussed than in a medical journal of such great influence and with such a wide circulation as THE LANCET?

Your correspondent takes a very narrow view as to what is meant by the nationalisation of Trinity College, Dublin. He defines it "as the complete de-sectarianising of it"; and he thinks the whole question would be settled if some Government would "proceed to eradicate all traces of sectarianism from the University of Dublin. To effect this latter purpose it would be essential to transfer in its entirety the Divinity school of Trinity College to the outside custody of the Chureh of Ireland, with a grant to that Church equivalent to that now made to the sectarian education at
Maynooth and elsewhere." No doubt, from a Trinity College point of view, this solution of the Irish University question would be an admirable one ; that is, Trinity College would continue as it is with the exception that the Divinity school would be transferred to the care of the Church of Ireland and would receive a grant equal to that of Maynooth. In other words, Ireland would possess a new Divinity school for a minority of Irishmen endowed as largely as Maynooth which educates theologically the clergy who minister to the wants of three-fourths of the inhabitants of Ireland. The Divinity school, separated from Trinity College, would thus become one of the most richly endowed theological institutions in the world. Would the British tax-payer calmly submit to pay as much for the education of the clergy for a population of 600,830 members of the Church of Ireland as for $3,549,745$ Roman Catholics? Or, to put it in another way, is the theological training of the clergy of 12.8 per cent. of the population of Ireland to cost as much as that of 75.4 per cent.?

But, Sirs, does your correspondent imagine that if Trinity College was desectarianised in the way he suggests the Irish University question would be at all settled? As everyone knows, it is a cardinal doctrine of the Roman Catholic Church that its members accept the teaching of their ecclesiastics as to what is dangerous to faith and morals. The removal of the Divinity school from Trinity College would still leave what your correspondent describes as a "thick Protesiant atmosphere" in that place which the Catholic Church teaches is inimical to the faith and morals of her sons, and bence Trinity College would be as much as ever under the ban of that powerful religious organisation.

There is, however, another and most important factor which your correspondent entirely ignores and which will have to be considered in any proposed settlement of Irish university education. If Trinity College is nationalised, not merely in the limited sense of having its Divinity school removed, and becomes a secular institution, how will this change meet the existing state of affairs as it concerns various Colleges and educational centres in Ireland outside Trinity College, what will then be the position of the Queen's Colleges of Belfast, Cork, and Galway, of Magee College, Derry, and of Victoria College, Belfast? How are these great educational institutions to be dealt with in this national university? Are they simply to send their students to Trinity College, Dublin, and close up their halls, or are they to remain as at present, let their students go to Trinity College, Dublin, for examination, and have no share or voice on the governing senate of this new national university? Is the great medical school of Belfast, one of the largest in Ireland, situated in a rapidly increasing city whose population now $\epsilon$ xceeds that of Dublin, to be quietly absorbed and take a subordinate position in this new national university? Does your correspondent really imagine that in these days of decentralisation, with new universities such as the Victoria, Birmingham, the Welsh, and the London, the hands of the clock are to be put back, and in Ireland everything of an educational nature is to be con. trolled from Trinity College? Is that institution to be the only place of collegiate education for young Irishmen, and, if so, how are the institutions already existing, such as the Queen's Colleges, Magee College, and Victoria College to stand related to the one national university? Would Scotchmen submit to have one university for the whole of their country situated in Edinburgh? Has not England revolted against university centralisation in London?

If Trinity College is to be really and truly nationalised something more than its mere "de-sectarianisation" will have to be attempted. 1. A truly national university must be so. constituted that, as your correspondent writes, its governing body, professors, fellows, and officials, as at present, are almost universally of one religious persuasion. 2. Irish Roman Catholics and the Presbyterians of Ulster must get a fair share in the governing senate, as well as in othermatters pertaining to the administration of the new university. 3. Arrangements will have to be made for the due recognition and adequate representation on the new national university of the various colleges and educational institutions. outside Trinity College in the provinces of Ireland. 4. A truly national university must meet the requirements and aspirations not of one sex alone, and hence all its degrees and honours must be open alike to women as to men. (Trinity College, in spite of frequent demands, has not advanced even this length, none of its degrees being open to women.) 